\title{
PRASASTI ANJUK LADANG DI NGANJUK JAWA TIMUR (SEJARAH DAN POTENSINYA SEBAGAI SUMBER PEMBELAJARAN SEJARAH)
}

\author{
Windi Ika Diahing Sari * \\ Anjar Mukti Wibowo*
}

\begin{abstract}
Abstrak
Penelitian ini bertujuan untuk mengetahui sejarah dan isi prasasti Anjuk Ladang serta potensinya sebagai sumber pembelajaran sejarah.

Lokasi penelitian ini berada di Museum Anjuk Ladang Kabupaten Nganjuk. Penelitian ini menggunakan pendekatan kualitatif. Sumber data yang digunakan yaitu sumber data primer dan sumber data sekunder. Teknik pengumpulan data menggunakan teknik observasi, wawancara, dan dokumentasi. Validasi yang digunakan untuk menguji kebenaran dan keabsahan data menggunakan tringgulasi sumber.

Berdasarkan penelitian yang dilakukan bahwa prasasti Anjuk Ladang dibuat pada tahun 937 masehi atau 859 saka atas perintah dari Mpu Sindok. Tujuan dibuat prasasti sebagai tetenger tentang adanya bangunan suci sebagai tugu kemenangan atau Jayastamba yang berupa Candi, bernama Candi Lor. Mpu Sindok memerintahkan pembuatan Jayastamba dan prasasti tersebut sebagai ungkapan rasa terimakasih kepada masyarakat Anjuk Ladang yang telah membantu selama peperangan melawan tentara melayu dari kerajaan Sriwijaya, sehingga berhasil memenangkan perang. Isi dari prasasti Anjuk Ladang adalah ditetapkannya daerah Anjuk Ladang sebagai sima swatantra, artinya daerah Anjuk Ladang dibebaskan dari kewajiban membayar pajak. Sebagai gantinya hasil bumi yang awalnya untuk membayar pajak digunakan untuk merawat bangunan suci yang berupa Candi Lor. Berdasarkan Kurikulum KTSP, Prasasti Anjuk Ladang dapat digunakan sebagai sumber pembelajaran sejarah pada satuan pendidikan SMP kelas VII semester 2 sebagai pengayaan materi dalam standar kompetensi 5. Memahami perkembangan masyarakat sejak masa Hindu-Budha sampai sekarang, tepatnya kompetensi dasar 5.1 Mendeskripsikan perkembangan masyarakat, kebudayaan dan pemerintahan pada masa Hindu-Budha, serta peninggalan-peninggalannya.
\end{abstract}

\section{Kata Kunci: Prasasti, Sejarah, Sumber Pembelajaran}

\section{Pendahuluan}

Indonesia merupakan negara dengan wilayah yang sangat strategis jika dilihat dari letak geografisnya. Letak geografis adalah letak suatu negara jika dilihat dari kenyataannya atau ditinjau dari posisi sebenarnya di permukaan bumi. Pengaruh letak geografis Indonesia terhadap keadaan alam yaitu Indonesia merupakan negara kepulauan yang merupakan pertemuan dari dua samudera besar (Samudera Pasifik dan Samudera Hindia) dan diapit daratan luas (Benua Asia dan Australia).

Wilayah Indonesia beriklim laut, sehingga pada masa lampau alat transportasi utama untuk berpindah dari satu pulau ke pulau yang lain adalah menggunakan kapal laut. Maka dari itu tidak heran jika di wilayah pesisir Indonesia terdapat kota-kota pelabuhan kuno yang telah berumur cukup tua.

* Windi Ika Diahing Sari adalah Alumni Mahasiswa Pendidikan Sejarah UNIVERSITAS PGRI MADIUN

* Anjar Mukti Wibowo adalah Dosen Prodi Pendidikan Sejarah UNIVERSITAS PGRI MADIUN 
Kota-kota pelabuhan tua di Indonesia merupakan jalur perdagangan yang sangat ramai. Banyak pedagang asing yang datang ke Indonesia untuk menjual barang dagangan seperti kain sutera, keramik, guci, dan lain-lain. Sedangkan pedagang Indonesia mereka menjual hasil bumi yang berupa rempah-rempah.

Kota pelabuhan tua di Indonesia merupakan jalur perdagangan yang sangat ramai. Banyak pedagang asing yang datang ke Indonesia untuk menjual barang dagangan seperti kain sutera, keramik, guci, dan lain-lain. Sedangkan pedagang Indonesia mereka menjual hasil bumi yang berupa rempah-rempah.

Dari hubungan perdagangan tersebut Indonesia mendapatkan banyak pengaruh kebudayaan asing, salah satunya dalam bidang agama. Hubungan dagang dengan India mengakibatkan Indonesia terpengaruh kepercayaan yang dianut oleh para saudagar dari India. Masuknya agama Hindu di Indonesia tentunya membawa berbagai dampak bagi Indonesia dalam bidang sosial dan budaya.

Sejak masuknya agama Hindu masyarakat Indonesia yang sebelumnya memiliki kepercayaan animisme dan dinamisme beralih memeluk agama Hindu. Di wilayah Nusantara sendiri mulai berdiri kerajaan-kerajaan kuno yang juga memeluk agama Hindu. Salah satu diantara kerajaan tersebut adalah Mataram Kuno.
Pada pembagian masa sejarah di Indonesia mengalami beberapa masa yaitu, masa prasejarah, masa sejarah, masa HinduBudha, masa Islam, masa kolonialisme, masa pergerakan nasional, masa orde lama, masa orde baru, hingga reformasi.

Masa sejarah adalah masa dimana manusia telah mengenal adanya tulisan. Hal itu terbukti dari adanya beberapa peninggalan sejarah yang berupa prasasti. Prasasti adalah sebuah artefak atau benda peninggalan sejarah yang tertulis, biasanya dipahatkan pada batu, logam, tanah liat, lontar atau kayu. Di Indonesia banyak ditemukan macam-macam prasasti diantaranya, prasasti Yupa, prasasti Kebun Kopi, prasasti Talang Tuwo, prasasti Kota Kapur, prasasti Anjuk Ladang dan masih banyak lagi peninggalan prasasti yang lainnya.

Benda peninggalan sejarah biasanya disimpan di sebuah museum. Museum merupakan tempat untuk menyimpan dan merawat benda-benda yang bernilai sejarah. Koleksi dari sebuah museum dapat beraneka ragam jenisnya, seperti bendabenda purbakala, peninggalan suatu kerajaan, peninggalan masa kolonialisme, peninggalan masa pergerakan nasional, peninggalan masa kemerdekaan, peninggalan masa orde lama, peninggalan masa orde baru dan masih banyak lagi peninggalan yang lain.

Salah satu prasasti yang telah disebutkan di atas, yaitu prasasti Anjuk 
Ladang merupakan koleksi dari musem Anjuk Ladang yang terdapat di Kabupaten Nganjuk, Jawa Timur. Menurut Darini (2013: 26) prasasti adalah pertulisan tentang maklumat atau keputusan resmi yang dipahatkan pada batu, lontar, atau pada logam yang dirumuskan menurut kaidah-kaidah tertentu serta ditandai dengan upacara.

Prasasti Anjuk Ladang merupakan peninggalan MPu Sindok semasa berkuasa di wilayah Jawa Timur. Pada masa itu Pu Sindok sedang berperang melawan tentara dari kerajaan Melayu, berkat bantuan dari masyarakat Anjuk Ladang $\mathrm{Pu}$ Sindok berhasil memenangkan perang tersebut. Prasasti Anjuk Ladang ini menyimpan sejarah yang penting bagi wilayah Kabupaten Nganjuk yaitu sebagai penanda awal berdirinya Kabupaten Nganjuk.

Sejarah prasasti Anjuk Ladang sangat menarik untuk dikaji lebih dalam lagi, hal itu karena prasasti ini kurang begitu terkenal bila dibandingkan dengan prasastiprasasti yang lain. Padahal prasasti Anjuk Ladang merupakan salah satu peninggalan $\mathrm{Pu}$ Sindok yang juga merupakan salah satu tokoh sejarah nasional Indonesia. Sehingga prasasti ini menarik untuk diteliti terkait dengan sejarah prasasti Anjuk Ladang, isi dan potensinya sebagai sumber pembelajaran sejarah.

\section{Tujuan Penelitian}

Adapun yang menjadi tujuan dari penelitian ini antara lain
1. Untuk mengetahui sejarah dari prasasti Anjuk Ladang di Nganjuk Jawa Timur.

2. Untuk mengetahui isi prasasti Anjuk Ladang di Nganjuk Jawa Timur.

3. Untuk menganalisis dan mendeskripsikan potensi prasasti Anjuk Ladang di Nganjuk Jawa Timur sebagai sumber pembelajaran sejarah.

\section{Tinjauan Pustaka}

\section{Prasasti}

a. Pengertian Prasasti

Prasasti adalah pertulisan tentang maklumat atau keputusan resmi yang dipahatkan pada batu, lontar, atau pada logam yang dirumuskan menurut kaidah-kaidah tertentu serta ditandai dengan upacara (Darini, 2013: 26). Pemerintah Kabupaten Madiun (1980: 28) mengungkapkan prasasti termasuk salah satu benda peninggalan purbakala terdiri dari karya tulis yang terpahat pada batu, logam, kulit binatang dan bahan-bahan lain.

Dalam Kamus Besar Bahasa Indonesia (1991: 786) prasasti berarti piagam (yang tertulis pada batu, tembaga, dan sebagainya). Prasasti adalah tulisan yang di pahatkan pada batu berisi catatan peristiwa penting kerajaan. Fungsi prasasti adalah memberikan peringatan atas peristiwa penting kepada generasi berikutnya. http://riviera17.blogspot.co.id/2012/09 /atradisi-sejarah-di-berbagaidaerahdi.html/ diakses 7-03-2016 11:11 WIB). 
Menurut uraian di atas prasasti merupakan artefak bertulis yang dipahatkan pada batu, logam, tanah liat, lontar, atau kayu yang memberikan berbagai macam informasi atas suatu peristiwa penting bagi generasi selanjutnya. Di Indonesia sendiri telah banyak ditemukan berbagai macam prasasti sebagai benda peninggalan bersejarah.

Beberapa prasasti tertua di Indonesia yang menunjukkan hubungan antara Indonesia dengan India antara lain prasasti Mulawarman di Kalimantan Timur yang berbentuk Yupa (tiang dari batu), prasasti Purnawarman dari kerajaan Tarumanegara di Jawa Barat. Isi Prasasti dituliskan dalam bentuk syair menggunakan huruf Pallawa dan bahasa Sansekerta.

Huruf tersebut diperkirakan menggunakan huruf yang umum dipergunakan pada tahun 400 dan bahasa Sansekerta merupakan bahasa resmi di India. Dari bukti-bukti yang ada dapat dipastikan bahwa pada masa Mulawarman dan Purnawarman terdapat pengaruh budaya India, termasuk dalam kehidupan keagamaan yaitu sebagai penganut agama Hindu (Darini, 2013: 26).

Prasasti-prasasti pertama yang ditemukan di Jawa berasal dari Pasundan sebelah utara, dekat kota Jakarta dan Bogor, dan ke barat di daerah Lebak.
Jumlahnya lima buah, yang membentuk satu rangkaian yang tampaknya koheren. Prasasti itu dibuat daam bahasa Sansekerta dan ditatah di atas batu karang besar bertulisan Pallawa, yang menandakan bahwa pembuatannya dilakukan pada abad ke-5. Disebutkan sebuah kerajaan bernama Taruma dengan raja Purnawarman, pengikut setia Wisnu. Atas perintahnya digali sebuah saluran di daerah Tugu, tidak jauh dari pelabuhan Tanjung Priok sekarang (Lombart, 1996: 13).

Prasasti-prasasti pertama daerah Jawa Tengah, yang muncul pada awal abad ke-8, mengungkapkan persaingan antara sesama raka atau rakaryan, yaitu penguasa yang telah berhasil menguasai sejumlah wanua atau "komunitas desa" dan berusaha meningkatkan prestisenya dengan memperbanyak bangunan suci (Lombard, 1996: 14).

Sementara di Jawa Timur wangsa yang dianggap berkuasa pada masanya adalah wangsa Isana yang didirikan oleh $\mathrm{Mpu}$ Sindok. Istilah wangsa Isana ditemukan dalam prasasti Pucangan, di bagian yang berbahasa Sansekerta. Prasasti itu dibuat era pemerintahan raja Airlangga pada tahun $1041 \mathrm{M}$.

b. Macam-macam Prasasti

Beberapa macam prasasti yang menunjukkan pengaruh Hindu-Budha adalah: 
1. Sima, yaitu prasasti yang berisi maklumat raja atau bangsawan dalam rangka pengukuhan daerah menjadi sima. Contoh: prasasti Anjuk Ladang.

2. Jayapattra, yaitu prasasti yang berisi keputusan hukum untuk pihak yang memenangkan suatu perkara. Contoh: prasasti Guntur 907 masehi.

3. Suddhapattra, yaitu prasasti yang berisi keputusan ikatan hutangpiutang, pelunasan, atau proses gadai. Contoh: prasasti Guntur 907 masehi.

4. Mantra-mantra, Hindu dan Budha, pada umumnya dipahatkan di atas lempengan tanah liat. Contoh: prasasti Jragung (E.S. Puar dalam Darini, 2013: 26).

c. Fungsi Prasasti

Secara umum fungsi prasasti antara lain, sebagai berikut:

1. Penghormatan kepada dewa. Dalam agama Hindu biasanya diawali dengan kata Ong Civaya,sedangkan agama Buddha diawali dengan kata Ong nama Buddhaya.

2. Angka tahun dan penanggalan, dalam penulisannya biasanya diawali dengan permulaan kata-kata: "Swasti Cri Cakawarsatita" yang berarti Selamat Tahun Caka yang sudah berjalan. Penamaan hari dalam satu minggu (tujuh hari) terdiri dari: Raditya (Minggu), Soma (Senin), Anggara (Selasa), Buddha (Rabu),
Respati (Kamis), Cakra (Jumat), dan Sanaiswara (Sabtu).

3. Menyebut nama raja, diawali dengan kata-kata "Tatkala Cri Maharaja Rakai Dyah ..." dan selanjutnya.

4. Perintah kepada pegawai tinggi, perintah ini biasanya melalui Rakryan Mahapatih dengan istilah "Umingsor ring rakryan Mahapatih ...", jadi raja tidak memberi perintah langsung.

5. Penetapan daerah sima (daerah bebas pajak), yang telah menolong raja atau menolong orang penting atau telah menolong rakyat banyak, misalnya, daerah penyeberangan sungai.

6. Sambhada (sebab musabab mengapa suatu daerah dijadikan sima).

7. Para saksi.

8. Desa perbatasan sima disebut juga "wanua tpisiring".

9. Hadiah yang diberikan oleh daerah yang dijadikan sima kepada raja, kepada pendeta, dan para saksi. Jika berupa uang, ukurannya adalah Su,berarti suwarna atau emas. Ma berarti masa dan Ku berarti kupang (1 $\mathrm{su}=16 \mathrm{Ma}=64 \mathrm{Ku}$ atau $1 \mathrm{Su}=1$ tail = 2 real), demikianlah ukuran uangnya.

10. Jalannya upacara.

11. Tontonan yang diadakan.

12. Kutukan (sumpah serapah kepada orang yang melanggar peraturan daerah sima). (Pramitahilala.blogspot.co.id/2012/0 3/fungsiprasasti. 
html diakses 09-01-2016 17.30 WIB).

\section{Sumber Pembelajaran}

a. Pengertian sumber pembelajaran

Sumber pembelajaran adalah sarana pembelajaran dan pengajaran yang sangat penting. Sudah menjadi keharusan bagi seorang guru untuk mengeksplorasi berbagai macam sumber untuk mendapatkan alat bantu yang tepat untuk mengajar dan melengkapi apa yang sudah disediakan di dalam buku cetak, untuk menambah informasi, untuk memperluas konsep, dan untuk membangkitkan minat peserta didik (Kochar, 2008: 160).

Sedangkan Sanjaya berpendapat bahwa sumber belajar memiliki 2 pengertian, (1) yang dimaksud sumber belajar adalah segala sesuatu yang dapat dimanfaatkan oleh siswa untuk mempelajari bahan dan pengalaman belajar sesuai dengan tujuan yang hendak dicapai (Sanjaya, 2009: 174), (2) yang dimaksud sumber belajar adalah segala sesuatu yang ada di sekitar lingkungan kegiatan belajar yang secara fungsional dapat digunakan untuk membantu optimalisasi hasil belajar (Sanjaya, 2008: 228).

Pendapat lain disampaikan oleh Slameto (1991: 150) sumber belajar adalah segala sesuatu yang memungkinkan seseorang belajar. Pengertian ini begitu luas, sehingga dalam pengembangan materi pengajaran perlu dibatasi bukannya segala sesuatu yang memungkinkan tetapi hanya yang digunakan untuk penyediaan fasilitas belajar.

Jadi yang dimaksud sumber pembelajaran adalah segala macam bahan yang dapat digunakan oleh siswa untuk mempelajari materi tertentu sesuai dengan tujuan yang hendak dicapai.

b. Jenis-jenis sumber pembelajaran

Sumber-sumber pembelajaran yang dapat digunakan oleh siswa meliputi:

1. Buku cetak;

2. Bahan bacaan tambahan;

3. Buku latihan;

4. Sumber-sumber pembelajaran yang terprogram;

5. Sumber-sumber referensi umum seperti ensiklopedia, surat kabar, atlas, pamflet, dan buku-buku terbitan pemerintah;

6. Buku-buku tambahan untuk bidang studi yang sedang dipelajari (Kochhar, 2008 : 161).

Sedangkan menurut Slameto (1991: 152-154) jenis-jenis sumber pembelajaran adalah:

1. Manusia Sumber (Orang, Masyarakat)

Merupakan juga sumber belajar adalah orang atau masyarakat yang direncanakan dalam kegiatan belajar mengajar, guru, konselor, administratur pendidikan, tutor dan sebagainya. 
2. Bahan pengajaran

Biasanya bahan ini berisi pesan. Bahan yang direncanakan sebagai sumber belajar dinamakan media pengajaran, yang meliputi: bahan cetak, film strip, slides, audia tape, film, peta, globe, chart (tabel bagan) dan sebagainya yang biasanya merupakan kombinasi dari semua sumber yang ada.

3. Situasi belajar (lingkungan)

Situasi ialah tempat dan lingkungan belajar mengajar biasanya tidak bersifat netral. Situasi dan lingkungan terutama sebagai sumber belajar adalah gedung sekolah, perpustakaan, laboratorium, auditorium, dan sebagainya.

4. Alat dan perlengkapan belajar

Diartikan sebagai alat dan perlengkapan untuk produksi, reproduksi, pameran, peragaan, simulasi dan sebagainya. Biasanya berbentuk peralatan seperti: proyektor, slide, OHP, proyektor film, komputer, videotape/ cassete recorder, pesawat radio, pesawat $\mathrm{TV}$, dan lain-lain.

5. Aktivitas (teknik)

Aktivitas sebagai sumber belajar biasanya selarasa dan kombinasi dengan sumber belajar yang lain. Aktivitas yang direncanakan sebagai sumber belajar lebih banyak merupakan teknik khusus yang memberikan faslitas belajar.

6. Adakalanya ditambahkan dengan sumber lain, yaitu: Pesan:
Pesan ini ialah ajaran/ informasi yang diteruskan oleh komponen lain dalam bentuk ide, fakta, arti dan data. Misalnya: semua bidang studi atau mata pelajaran seperti IPS/ Sejarah, IPA/ Ilmu Fisika, Bahasa, Politik, Ekonomi, Logika, Etika, Kesehatan dan lain-lain.

\section{Metode penelitian}

\section{A. Lokasi Dan Waktu Penelitian}

Penelitian ini dilaksanakan di Museum Anjuk Ladang Jalan Gatot Subroto Kecamatan Nganjuk Kabupaten Nganjuk, dimana prasasti Anjuk Ladang merupakan salah satu koleksi dari museum tersebut. Penelitian dilaksanakan selama 5 bulan yaitu mulai bulan Februari sampai Juni 2016.

\section{B. Pendekatan dan Jenis Penelitian}

Pendekatan ini menggunakan penelitian kualitatif. Pendekatan kualitatif merupakan metode penelitian yang digunakan ditunjukan untuk mendeskripskan dan menganalisa fenomena, peristiwa, aktifitas sosial, sikap, kepercayaan, persepsi, pemikiran orang baik secara individual ataupun kelompok (Sukmadinata, 2007: 60).

Penelitian ini menggunakan pendekatan induktif. Peneliti melakukan pengamatan terhadap prasasti Anjuk Ladang yang berada di museum Anjuk Ladang tempat dimana prasasti tersebut disimpan. Kemudian menarik kesimpulan secara umum dengan dukungan dari beberapa 
informasi, sehingga data yang akan diperoleh bersifat deskriptif.

Jenis penelitian yang dilakukan yaitu jenis penelitian deskriptif. Bagian deskriptif dalam catatan data ini meliputi potret subjek, rekonstruksi dialog, deskripsi keadaan fisik, struktur tentang tempat, dan barang-barang lain yang ada di sekitarnya. Demikian juga, catatan tentang berbagai peristiwa khusus (termasuk siapa yang terlibat dengan cara bagaimana, gerakgeriknya,) dan juga tingkah laku atau sikap penelitiannya) (Sutopo, 2002:74).

Pendekatan ini cocok untuk meneliti sejarah prasasti Anjuk Ladang dan potensinya sebagai sumber pembelajaran sejarah. Penelitian ini dilaksanakan dengan menganalisis data yang diperoleh dari wawancara, dokumentasi, dan observasi lapangan.

\section{Sumber Data}

Sumber data penelitian merupakan sumber data primer dan sumber data sekunder sebagai berikut:

1. Sumber Data Primer

$$
\text { Umar (2011: }
$$

mengemukakan bahwa data primer merupakan data yang diperoleh dari sumber pertama baik dari individu atau perseorangan seperti hasil dari wawancara atau hasil pengisian kuisoner yang biasa dilakukan oleh peneliti. Data yang didapat berupa hasil wawancara dengan informan.
Sumber lisan ini dapat diperoleh dengan mendeskripsikan tertulis hasil dari pengamatan atau wawancara. Informan penelitian yaitu petugas museum atau orang yang dianggap mengetahui sejarah prasasti Anjuk Ladang di Nganjuk Jawa Timur.

2. Sumber Data Sekunder Sumber data sekunder menurut Silalahi (2003: 57) adalah data penelitian yang diperoleh secara tidak langsung atau melalui media perantara yang diperoleh maupun dicatat oleh pihak lain. Sumber data sekunder yang digunakan dalam penelitian ini adalah buku profil Kabupaten Nganjuk.

\section{Teknik Pengumpulan Data}

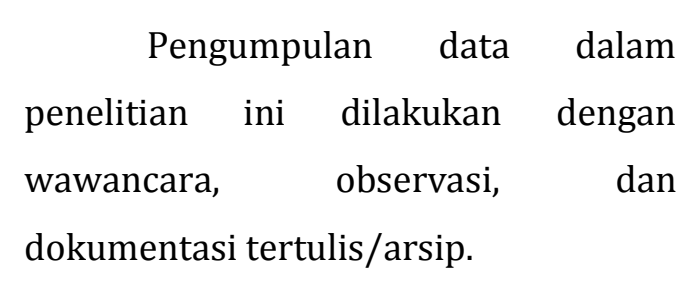

1. Wawancara

Esterberg (dalam Sugiyono, 2008: 233) mengemukakan beberapa macam wawancara, yaitu wawancara terstruktur, semiterstruktur, dan tidak terstruktur. Penelitian menggunakan jenis wawancara tidak terstruktur. pedoman wawancara yang digunakan berupa garis-garis besar permasalahan yang akan digunakan.

Metode tersebut digunakan dalam penelitian ini dikarenakan 
peneliti akan melakukan wawancara kepada informan yang dianggap sebagai salah satu sumber yang bisa menjawab rumusan masalah penelitian. Peneliti perlu menjelaskan kepada responden tentang tujuan penelitian. Sebelum wawancara akan, menyusun pedoman wawancara sebagai salah satu kode etik wawancara.

2. Observasi Langsung

Hal senada juga disampaikan oleh Nazir (2009: 175) observasi langsung atau dengan pengamatan langsung adalah cara pengambilan data dengan menggunakan mata tanpa ada pertolongan alat standar lain untuk keperluan tersebut.

Jenis observasi yang dipilih adalah non-partisipan. Peneliti tidak ikut dalam kehidupan obyek yang diobservasi, dan secara terpisah berkedudukan selaku pengamat.

Peneliti hanya bertindak sebagai pengamat saja. Peran peneliti di lokasi bersifat pasif, sebab kehadirannya sebagai pengunjung museum, dan tidak berpengaruh pada yang diamati. Halhal yang perlu diamati atau diobservasi diantaranya yaitu museum Anjuk Ladang dan prasasti Anjuk Ladang.

3. Dokumentasi

Jenis dokumentasi yang dipilih yaitu dokumentasi primer dan dokumentasi sekunder. Dokumentasi primer diperoleh melalui hasil observasi dan wawancara kemudian dideskripsikan dalam penelitian ini.

Adapula sumber sekunder yang dipakai dalam penelitian berasal dari selain manusia, diantaranya profil prasasti Anjuk Ladang di museum Anjuk Ladang Kabupaten Nganjuk.

\section{E. Prosedur Penelitian}

Tahapan dalam penelitian ini tersusun sebagai berikut:

1. Tahap Persiapan

Tahap ini merupakan bagian dari menetapkan fokus penelitian. Kegiatan ini dimulai dengan menetapkan tema dan judul yang akan menjadi obyek penelitian. Selain itu peneliti juga meminta ijin kepada pengelola obyek tersebut. Setelah menentukan tema, selanjutnya menjelaskan kondisi awal obyek penelitian.

\section{Tahap Penelitian}

Tahap ini dilakukan pengumpulan data, pengolahan data, dan analisis data. Peneliti mendapatkan data dari berbagai sumber, dari hasil wawancara, sumber dokumen, dan observasi langsung.

Data yang terkumpul akan mampu mengetahui hasil awal sesuai dengan tujuannya. Jika ditemukan hasil yang kurang sesuai, maka akan dilakukan analisis berkelanjutan sehingga hasil penelitian sesuai dengan kenyataan.

\section{Tahap Laporan}

Pada tahap akhir merupakan tahap penyelesaian laporan atau penyajian 
data. Penyusunan laporan didasarkan pada hasil analisis data yang sudah didapatkan pada tahap sebelumnya. Laporan atau sajian dilakukan secara benar dan tersusun sistematis. Selain itu data yang disajikan merupakan data yang sesuai dengan fakta dan dapat dipertanggung jawabkan kebenarannya.

\section{F. Teknik Keabsahan Data}

Untuk mendapatkan data yang valid, peneliti menggunakan teknik validitas data sebagai berikut:

1. Trianggulasi metode adalah pengumpulan data yang sama dengan menggunakan metode pengumpulan data yang berbeda, serta diusahakan mengarah pada sumber data yang sama untuk menguji kemantapan informasi. Penggunaan metode pengumpulan data yang berbeda, dan bahkan lebih jelas untuk diusahakan mengarah pada sumber data yang sama untuk menguji kemantapan informasinya. Misalnya, untuk memantapkan validitas data mengenai suatu keterampilan seseorang dalam bidang tertentu. Peneliti menggunakan metode pengumpulan data berupa kuesioner. Kemudian dilakukan wawancara mendalam pada informan yang sama dan hasilnya diuji dengan pengumpulan data sejenis dengan menggunakan teknik observasi pada saat orang tersebut melakukan kegiatan atau perilakunya (Sutopo, 2002: 80).

2. Trianggulasi sumber data adalah mengumpulkan data dari berbagai sumber data digunakan untuk menguji kebenaran tentang pelaksanaan pembelajaran Sejarah. Cara ini mengarahkan peneliti agar dalam mengumpulkan data, ia wajib menggunakan beragam sumber data yang tersedia. Artinya, data yang sama atau sejenis, akan lebih mantap kebenaranya bila digali dari berbagai sumber data yang berbeda. Trianggulasi sumber data yang memanfaatkan jenis sumber data yang berbeda-beda untuk menggali data yang sejenis (Sutopo, 2002: 79).

\section{G. Teknik Analisis Data}

Analisis data seperti pendapat Patton (dalam Moleong, 2012: 280) adalah proses mengatur urutan data, mengorganisasikannya ke dalam suatu pola, kategori, dan satuan uraian dasar.

Masalah reduksi data, penyajian data, dan penarikan kesimpulan atau verifikasi menjadi gambaran keberhasilan secara berurutan sebagai rangkaian kegiatan analisis yang saling susul menyusul. Pada prinsipnya analisis data akan bergerak pada tahap reduksi data, tahap penyajian data, dan tahap penarikan kesimpulan. 


\section{Pembahasan}

\section{A. Sejarah Prasasti Anjuk Ladang}

Prasasti adalah pertulisan tentang maklumat atau keputusan resmi yang dipahatkan pada batu, lontar, atau pada logam yang dirumuskan menurut kaidahkaidah tertentu serta ditandai dengan upacara (Darini, 2013: 26). Prasasti merupakan salah satu benda peninggalan sejarah yang sangat penting.

Adanya prasasti menunjukkan bahwa Indonesia telah mengalami peralihan dari masa praaksara ke masa aksara. Prasasti biasanya berisi tentang kejadian penting yang terjadi di masa lampau. Di Indonesia telah banyak ditemukan prasastiprasasti yang merupakan peninggalan kerajaan-kerajaan di masa lalu seperti prasasti Yupa yang ditemukan di Kutai Kalimantan Timur, prasasti Pasir Awi di Bogor Jawa Barat, prasasti Plumpungan di Salatiga Jawa Tengah, prasasti Anjuk Ladang di Nganjuk Jawa Timur.

Dari semua prasasti di Indonesia, salah satu prasasti yang menarik untuk diteliti adalah Prasasti Anjuk Ladang yang ditemukan di Jawa Timur. Tepatnya sekitar tiga sampai empat kilometer arah selatan dari pusat Kabupaten Nganjuk yaitu di Desa Candirejo Kecamatan Loceret. Prasasti ini ditemukan di dekat sebuah candi yang bernama Candi Lor. Menurut sejarah, pembuatan prasasti ini tidak terlepas dari seorang tokoh yang berasal dari Mataram yang bernama Mpu Sindok.
Mpu Sindok adalah pendiri wangsa Isyana di Jawa Timur. Istilah wangsa Isyana ditemukan dalam prasasti Pucangan yang dikeluarkan oleh raja Airlangga tahun 963 saka (1041 masehi). Pada masa pemerintahan Rakai Layang dyah Tlodhong dan Rakai Sumba dyah Wawa berkedudukan sebagai rakryan mapatih $i$ halu dan rakryan mapatih i hino. Kedudukan tersebut biasanya hanya dapat dijabat oleh kerabat dekat raja. Sehingga dapat diketahui bahwa Mpu Sindok adalah anggota wangsa Syailendra.

Kerajaan Mataram di Jawa Tengah mengalami kehancuran karena letusan Gunung Merapi yang mahadahsyat, sehingga dalam anggapan para pujangga hal itu dianggap sebagai pralaya. Sesuai dengan landasan kosmogonis kejaan-kerajaan kuno, maka harus dibangun kerajaan baru dengan wangsa yang baru pula. Oleh karena itu, Mpu Sindok membangun sebuah kerajaan baru di Jawa Timur dan dianggap sebagai cikal bakal wangsa baru yaitu wangsa Isyana (Poesponegoro, 2008: 185).

Mpu Sindok adalah raja pertama Kerajaan Medang periode Jawa Timur yang bergelar Sri Maharaja Rakai Hino Sri Isana Wikramadharmo tunggadewa. Mpu Sindok memiliki permaisuri yang bernama Sri Prameswari Dyah Kebi, putri dari Rakai Bawa. Menurut Poerbatjaraka, Rakai Bawa adalah Dyah Wawa. Maka Mpu Sindok sebagai menantu Dyah Wawa (Adji, 2012: 48). Setelah $\mathrm{Mpu}$ Sindok memindahkan 
pusat kerajaan dari Jawa Tengah ke Jawa Timur, beliau mendapat serangan dari tentara melayu yaitu pasukan dari kerajaan Sriwijaya. Dalam peperangan tersebut Mpu Sindok dibantu oleh penduduk Anjuk Ladang sehingga berhasil memenangkan perang.

Sebagai ungkapan rasa terimakasih $\mathrm{Mpu}$ Sindok membangun sebuah tugu kemenangan Jayastamba beupa bangunan candi yang disebut Candi Lor. Prasasti Candi Lor sering disebut prasasti Anjuk Ladang. Prasasti ini merupakan sumber sejarah yang menjelaskan salah satu puncak peranan Nganjuk dalam mata rantai sejarah Indonesia. Prasasti Candi Lor dikeluarkan oleh Maharaja Mpu Sindok pada tahun ke sembilan masa pemerintahannya yaitu tahun 859 saka atau 937 masehi.

Prasasti Anjuk Ladang itu mengandung keterangan tentang adanya serbuan dari Malayu (Sumatera). Tentara Malayu bergerak sampai dekat Nganjuk, tetapi dapat dihalau oleh pasukan raja di bawah pimpinan Mpu Sindok yang waktu itu masih belum menjadi raja. Atas jasanya yang besar terhadap kerajaan itu $\mathrm{Mpu}$ Sindok kemudian diangkat menjadi raja (J. G. de Casparis dalam Poesponegoro 2008: 188).

Mengenai arti dan makna dari kata Anjuk Ladang yaitu:

1. Anjuk: bearti tinggi, tempat yang tinggi atau dalam arti simbolis adalah mendapat kemenangan yang gilang gemilang

2. Ladang: berarti tanah atau daratan (J.G. de Casparis dalam Harimintadji 2003: 50). Mengingat pentingnya prasasti Anjuk Ladang ini bagi sejarah Nasional Indonesia umumnya dan bagi Kabupaten Nganjuk khususnya, maka sangatlah pantas apabila tanggal dibuatnya prasasti Anjuk Ladang juga dijadikan tanggal berdirinya Kabupaten Nganjuk yaitu tanggal 10 April 937.

Dari berbagai data sejarah yang ada, diperlukan alasan-alasan kuat untuk menentukan Hari Jadi Nganjuk, sehingga dapat mengungkapkan jati diri serta menjadi ilham dalam membangun daerah ini, dan sekaligus dapat menjadi kebanggaan masyarakat di kemudian hari.

Untuk itu, ada beberapa hal yang perlu dijadikan dasar penentuan hari jadi tersebut, yaitu:

1. Adanya bukti tertulis tertua yang menunjukkan hubungan historis arkeologis dengan toponimi Nganjuk di daerah yang dalam perkembangan sejarahnya secara kontinyu menjadi Kabupaten Nganjuk. Sumber tertulis itu merupakan sumber utama (primer) dan sejaman, asli, gayut dan kredibel

2. Sumber tertulis berupa prasasti tertua yang menyebutkan sejumlah toponimi (nama tempat) yang dapat dilacak kembali di daerah yang kemudian hari berkembang menjadi wilayah 
administratif Kabupaten Nganjuk. Dalam kategori ini termasuk prasasti atau sumber tertulis lain walaupun tidak memuat data yang berkaitan langsung dengan toponimi Nganjuk, namun terdapat di daerah Kabupaten Nganjuk sekarang

3. Sumber tertulis dan lisan yang berisi ingatan kolektif penduduk Kabupaten Nganjuk, yang secara turun temurun dilestarikan dalam bentuk mitos, legenda dan cerita rakyat (folklor) sepanjang mengenai asal-usul nama daerah, seorang tokoh cikal bakal dalam pemerintahan, kemasyarakatan serta kebudayaan yang dapat dibandingkan kebenarannya dengan sumber lain

4. Bukti yang berupa bangunan, monumen, patung atau artefak lain, yang dijumpai di daerah Nganjuk yang secara kontinyu dapat dilacak sejarahnya dari masa lalu yang tertua

5. Sumber berupa dokumen tertua sepanjang menyangkut asal-usul pemerintahan daerah Kabupaten Nganjuk, yang mengandung nilai sejarah desa, peristiwa kepahlawanan, serta halhal yang dapat menumbuhkan kebanggaan masyarakat (Harimintadji 2003: 34-35).

Prasasti Anjuk Ladang merupakan salah satu benda cagar budaya yang wajib untuk dilestarikan bersama. Sejarah panjang prasasti Anjuk Ladang yang dijadikan sebagai hari jadi bagi Kabupaten Nganjuk merupakan bukti bahwa benda-benda peninggalan sejarah tidak dapat diabaikan begitu saja keberadaannya, namun benda-benda tersebut harus dijaga sebagai warisan sejarah Nusantara.

\section{B. Isi Prasasti Anjuk Ladang}

Prasasti Anjuk Ladang dibuat pada tahun 859 saka atau 937 masehi, hal itu berarti prasasti ini telah berusia 1079 tahun saat ini. Maka tidak heran jika ada beberapa bagian yang tidak terbaca oleh para ahli karena mengalami kerusakan termakan usia. Tapi dari bagian yang terbaca maka dapat diketahui inti dari prasasti tersebut.

Prasasti Anjuk Ladang berisi tentang penetapan wilayah Anjuk Ladang sebagai tanah perdikan sima swatantra. Artinya wilayah Anjuk Ladang dibebaskan dari tanggung jawab membayar pajak. Tetapi sebagai gantinya upeti yang digunakan untuk membayar pajak dialihkan untuk merawat bangunan suci Jayastamba Candi Lor.

Wilayah sekitar Candi Lor dijadikan tanah perdikan sima swatantra sebagai wujud rasa terima kasih Mpu Sindok kepada masyarakat Anjuk Ladang yang telah berjasa membantu dalam peperangan melawan pasukan Melayu sehingga pasukan tersebut dapat dikalahkan. Transkripsi 
prasasti Anjuk Ladang dibuat oleh J.L.A. Brandes tahun 1887 dan dimuat dalam buku Oud Javansche Oorkoden (kumpulan prasasti berbahasa Jawa Kuno) yang ditebitkan oleh N.J. Krom pada tahun 1913.

Sedangkan transliterasi secara lengkap sampai sekarang belum pernah dilakukan. Para ahli yang meneliti prasasti Anjuk Ladang pada umumnya hanya membahas bagian tertentu atau membicarakan garis besarnya saja. Prasasti ini memuat pada tulisan depan (Recto) sebanyak 49 baris dan bagian belakang (Verso) sebanyak 14 baris (Harimintadji 2003: 39).

Di dalam prasasti Anjuk Ladang tahun 859 saka (937 M) dikatakan bahwa raja Mpu Sindok telah memerintahkan agar tanah sawah kakatikan (?). Di Anjuk Ladang dijadikan sima, dan dan dipersembahkan kepada bhatara di sang hyang prasada kabhaktyan di Sri Jayamerta, dharma dari Samgat Anjuk Ladang. Itu merupakan anugerah raja bagi penduduk Desa anjuk Ladang (Poesponegoro 2008: 188).

Dari prasasti Anjuk Ladang ada bagian yang tidak terbaca karena rusak termakan usia yang sudah sangat lama. Namun bagian yang dapat dibacapun tidak semua dapat diterjemahkan, terlebih lagi bahasa yang digunakan untuk menerjemahkan adalah bahasa
Belanda. Berikut isi prasasti Anjuk Ladang yang dapat terbaca, yaitu:

1. Swasti cakawarsatita 857 caitramasa tithi dwadacicuklapaksa

2. naksatra barunadewata brahmayoga kolawakarana irika di (wa)

3. Sanya ajna cri mhraja pu sindok cri icanawikrama dharmmotunggadewa tinadah rakryan mapighai kalih ( $r a$ )

4. (ke hino pu sahasra, rake) wka pu balicwara umingso i rakai kanuruhan pu da kumonakan ikanang Imah sawah kakatikan

5. marpanakna i bhatara i sang hyang prasada kabhaktyan i dharmma samgat pu anjuk-ladang

6. cri maharaja $i$ cri jayamrta sima punpunana bhatara

7. pratidina mangkana cri maharaja rikanang sawah kakatikan

8. $n i$ bhatara $i$ sang hyang $i$ sang hyang prasada kabhaktyan $i$ cri jayamrta mari ta yan Imah sawah kakati ( $k a)$

9. n iyanjukladang tutugani tanda sambahanda ikanang rama iyanjukladang tutugani tanda kanugrahan de cri maharaja manglanga

10. $i$ saprana $i$ satahun satahun matangnyan papinda lamwit 6 (?) ikanang sawah kakatikan iyanjukladang tutuga 
11. i tan wuang i tani rama dumadyakan ikanang katik samangkana ya ta matangnyan inanugrahanikanang rama iyanjukladang

12. katik de cri maharaja tamolaha magawai ma 4 madrwyahaji Irin mas su 12 i satahun satahun

13. mangkana () nn () nyanugraha cri maharaja irikanang rama iyanjukladang tutugani tanda tlas mpageh tan kolahulaha

14. yakapa () ya tka i dlahaningdlaha parnnahaningkanang Imah unggwani sang hyang prasada athetherang jayastama

15. muang ikang sawah kakatikan iyanjukladang tutugani tanda swatantra tan katamana deni winawa sang mana katrini pangkur

16. muang saprakara ning mangilala drwyahaji ing dangu micra paramicra wuluwulu prakara pangurang kring padam manimpiki paranakan limus galuh

17. pangaruhan taji watu tajam sukun halu-warak rakadut paninglay katanggaran tapahaji airhaji malandang

18. tangkil salwit watu walang pamanikan maniga sikpan rumban wilang wanua wiji kawah tingkes mawi manambangi juru

19. tuha judi juru jalir pabisar pagulung pawungkunung pulung padi tuhadagang micra hino wli hapu wli wadung wli tambang wli panjut wli harng

20. urutan dampulan tpung kawung sungsung pangurang pasukalas panguyaan sapan wilutngkung panginingi paamawacya hopan $n$

21. panusuruh mahaliman kdi walyan mapaadahi widu mangidung sambal sumbul hulun haji pamrsi watek i jro ityewamadi tan

22. Imah sawah sima kakatikan iyanjukladang tutugani tanda kaiwala bhatara $i$ sang hyang prasada kabhaktyan sanghyang (dha) rmma i cri jayamrta (atah pramana i skabeh)

23. wya hajinya magong madmit ka (beh sa) mangkana ikanang sukha dukha kadyanggani mayang tan mawuah walu rumambat sing natar wipati wangkai kabunan rah kasawur ing dalan

24. (wak) capala duhilatan hidu kasirat hasta catra mamijilakan wuri ning kikir mamuk mamumpang ludan tuttan angcapratyangca danda kudanda bhan (dihaladi)

25. i sang hyang prasada kabhaktyan sang hang dharmma i cri jayamrta atah parana ni drwya hajinya kunang ikanang micra manambul manawaring manglaka

26. la mangdy manghapu manghrangmanula wungkudu 
magawai rungki payung wlu mopih akajang magawai isi mamubut ma

27. manababmamisandung anuk makala kapuaya tribhagan dwrya hajinya saduman umara $i$ bhatara $i$ sang hyang prasada kabhaktyan $i$

28. iyanjukladang tutugan $i$ tanda $i$ jayamrta saduman umara irikanang punta ja (ta) ka maakmitan sima i cri jayamrta saduman

29. laladwyra haji micra irikanang kala mangangseakan samgat anjukladang pasambah i cri maharaja ma ka l wdihan ganjar haji yu I rakryan

30. (kalih) rakai hino pu sahasra rakai wka pu balicwara inangseakan pasak-pasak mas su 18 wdihan yu l sowang sowang rakai sirikan pu ma

31. rakai kanuruhan $p u$ ta inangsean pasakpasak mas su l ma 4 wdihan yu I sowang sowang samgat pikatan pu ca tiruan

32. nta taratir tataran pu bingu pulung watu pu kikas inangsian pasak-pasak mas I wdihan yu l sowang sowang juru siki pu bawlu amr pu manak

33. mpit pu wayan manghuri pu suduya inangsian pasakpasak ma l wdihan yu l sowang sowang pa kuba hawang kuyalangka pu babra anju sanda pu dula

34. inangsian pasakpasak mas 4 wdihan yu l sowang sowang wadihati $p u$ dinakara akudur pu dwaj inangsian pasakpasak ma l wdihan yu l sowang so

35. wang tuhan $i$ widihati miramirah sang tambalang halaran sang dulangtuhan i makudur basatpusan salulahan winaih pasakpasak ma wdihan yu $l$

36. sowang-sowang panguruhan $i$ widihati sang parapak manunggu sang basu pangurang i makudur rakwel saturung winaih pasak-pasak mas wdihan yu l sowang

37. sowang sang tuhan ing pakaranan makabaihan juru kanayakan i haji pu kunda juru wadwa rare rakaai sumbun juru kala

38. citralekha walu pu dangha an pajuar i hino kandamuni dangacarayya jale $i$ wka biriwih dangacarayya nanaya $i$ sirikan

39. Madander dangacarayya prdu $i$ bawang dangacaryya netra $i$ kanuruhan sang rama $i$ tirun wadihati

40. i pakudan sang rakwil kring satagan durang winaih pasakpasak ma su 1 ma 4 kinabaihan nira sang citralekha i cri maharaja trawaruk (asu of rsu?)

41. kadudut wimala balukit winaih pasakpasak mas su $l$ ma 4 kinabaihan-nira pinghe kalih $h$ sa kuci sang kini winaih pasak pa

42. sak ma 2 ku 2 wdihan yu l sowang sowang parujarnya pingsor hyang si 
pakudan paskaran si badug winaih ma (s) ku l wdihan hlai sowang

43. sowang wahu ikidulning turus sang gutul kutesabi intih winaih pasak mas lku 4 widihan sowang sowang pangangka

44. kudur ma su I ma 4 wdihan yu l saji sang hyang brahma mas 10 kaharan simsim prasada mas l angsun buah kunda mas saji sang hyang

45. wungkul susuk wdihan yu 4 (?) saji sang hyang kulumpang wdihan yu 4 saji sang hyang prthiwi kan wlah l kulambil $\quad l$ saji sang hyang a

46. kaca wdihan yu l pangisi tambukur ma I saji sang hyang caturddeca su l daksina ma 8 kinarmma sng hyang kudur ma 4 wdihan yu 1

47. $k$ mandala su $l$ ma 4 karamnnire wadihati su l mara karamnnire makudur su 1 ma 4 saji ning momahumah wsi samarja tambaga ga

48. ngsa prakara in () as samasanya su 2 ma 12 tu pinakamanggalya rikang susukan sima sira mpu mahaguru 1 sang hyang dharmmaya

49. ing kacaiwan ing tanjung muang sira mpu goksandha $i$ sang hyang dharmma i jayamrta pangapa i sang hyang wihantau $i \quad$ nja Achterzidje

23. bhuwur dandal margganayikdolalambo winaih pasak ma l sowang i tlasning mawaih pasakpasak $i$ tanda rakryan muang pinghai wahuta rama

24. ing dangu pinarnnah ikanang saji ing sang makudur $i$ sor ning witana $i$ tugah ni paglaran sawidhi widhana sakramaning manusuk

25. magaskara sang hyang susuk watu kulumpang mamuja $i$ sang hyang brahma malawu ing dacadeca mangdiri ta sang makudur ma li mottarasangga bandhana ta

26. lawan sang wadihati manganjali $i$ sang hyang teas malungguh $i$ sor ning witana ma () lan padahumarepakan sang hyang susuk watu hinare

27. pinghai wahuta rama tpi siring kapua mapangalih sopacara manguyut ta sang makudur manetetek guluni ( $\mathrm{ng}$ ) hayam linandesakan ing kulumpung mamantingakan

28. hangtlu ing watu sima mamangmang manapathe saminangmang nira ring dangu i kateguhkna sang hyang watu sim ikana lingnira indah ta kita kamung hyang i cri haricandana a (ga)

29. sti maharsi purwa daksina paccimottaramddhya urddhmadhah rawicaciksiti jalapawana jayamanakaca dharmma ahoratra yahwu jaya yaksa raksa

30. sa pisaca petrasura garuda gandharwwa bhuta kinnara 
mahoraga catur kapila yamabruna kuwera basawa muang putradewata pancakucika nandicwara ma

31. nagaraja durggadewi caturancra ananta surendra ananta hyang kala mrthyu gana bhuta kita prasiddha mangraksa kadatun rahyang ta $i$

32. mdang i bhumi mataram i kita umilu manarira umasuk i sarw wacarira kita ca (ka) la saksibhuta tumon madohlawan mapare ing rahina ing wngi at renge

33. kang samaya sapatha sumpah pamangmang mami i kita hiyang kabeh yawat ikanng wang duracara tan magam tan makmit irikaing hakani

34. hyang kudur brahmana ksatriya wecya sudra hajuan hulun matuha raray lakilaki wadwan wiku grhastha pinghai wahuta rama nayaka

35. umulhulh ike Imah sawah kakatikan iyanjukladang tutugani tanda sima inarpanakan i samgat anjukladang

36. $i$ bhatara sang hyang prasada kabhaktyan i cri jayamrta ing dlaha hlam an babaka (Harimintadji 2003: 202-207).

Skema struktur Prasasti Anjuk Ladang scara garis besar adalah sebagai berikut:

1. Kalenderis, unsur penanggalan

2. Raja yang memrintahkan pembuatan prasasti yaitu Sri Maharaja Mpu
Sindok Isana Wikrama

Dharmmotunggadewa

3. Birokrasi, struktur dan pejabat pemerintahan terutama pejabat yang dilibatkan dalam pembuatan prasasti, mulai dari pejabat tinggi atau pejabat Pemerintahan Pusat, pejabat menengah sampai pejabat tingkat rendah yaitu pejabat desa

4. Sambandha, alasan (latar belakang) pembuatan prasasti

5. Mangilala dwryhaji, yaitu pejabatpejabat pemungut (penarik) pajak yang sejak dikeluarkannya prasasti tidak lagi diperkenankan memasuki desa yang telah dijadikan desa suci (sakral) atau desa otonom (perdikan) bebas pajak dan disebut sima swatantra. Para pemungut pajak tersebut jumlahnya cukup banyak, dalam prasati Anjuk Ladang disebutkan lebih dari 60 pejabat, diantaranya yang terkenal adalah: Pangkur, Tawan, Tirip

6. Pasak-pasak, yaitu hadiah atau persembahan yang disampaikan oleh sekelompok orang yang memperoleh anugerah dari Sang Maharaja (dalam hubungannya dengan pemberian perdikan atau status otonom, bebas pajak desa Anjuk Ladang) kepada pejabat-pejabat pemerintahan yang hadir dalam upacara. Dalam prasasti Anjuk Ladang, jumlah pejabat penerima pasak ada 43 orang. Pasak- 
pasak itu berwujud emas dalam berbagai ukuran/satuan dan pakaian. Besar kecilnya pasak-pasak disesuaikan dengan tinggi rendahnya pejabat yang menerima

7. Upacara ritual, yaitu upacara penetapan Anjuk Ladang sebagai desa perdikan sima swatantra yang dilakukan dengan melaksanakan seperangkat upacara suci (ritual). Upacara ini melibatkan sejumlah petugas, alat-alat dan barang-barang sesaji. Upacara tersebut disebut Manasuk Sima. Benda-banda sesaji dan alat-alat yang dipergunakan antara lain: telur, ayam, kepala kerbau, alat-alat dapur, kalumpang dan lain-lain. Sedangkan petugas upacara disebut Madukur

8. Sapatha atau kutukan, sebagai upacara penutup adalah kutukan atau sumpah serapah bagi siapa saja yang melanggar atau tidak mematuhi isi prasasti, serta doa keselamatan dan kesejahteraan bagi yang mematuhinya. Kutukan itu diungkapkan dalam berbagai pernyataan yang menyeramkan dan mengerikan. Misalnya: semoga dikoyak-koyak badannya oleh para desa, dicaplok harimau bila masuk hutan, dimakan buaya bila mandi di sungai, disambar petir bila hujan, dipathuk ular berbisa, disiksa Dewa Maut, dimasukkan dalam bejana penyiksaan (tamragumukha) di neraka nanti bila sudah mati (Harimintadji 2003: 39-41).

Isi prasasti Anjuk Ladang memang tidak semua dapat dibaca karena ada beberapa bagian yang sudah rusak atau aus. Akan tetapi dari bagian yang terbaca dapat diketahui makna secara garis besar atau isi dari prasasti tersebut.

\section{Potensi Prasasti Anjuk Ladang Sebagai Sumber Pembelajaran Sejarah}

Salah satu benda peninggalan sejarah tentunya prasasti Anjuk Ladang memiliki arti penting bagi pemerintah Kabupaten Nganjuk dan juga masyarakat Nganjuk sendiri. Hal ini dapat kita ketahui dari sikap pemerintah Kabupaten Nganjuk dan masyarakatnya terhadap keberadaan prasasti Anjuk Ladang.

Prasasti Anjuk Ladang mamiliki peranan yang besar, terutama dalam sejarah Kabupaten Nganjuk. Selain itu, ditetapkan sebagai tanggal berdirinya Kabupaten Nganjuk. Ini membuktikan bahwa Prasasti Anjuk Ladang ini memang layak untuk dijadikan sebagai sumber pembelajaran sejarah. Untuk membuktikannya kita harus terlebih dulu mengetahui sikap pemerintah dan masyarakat terhadap prasasti tersebut serta upaya-upaya yang telah ditempuh pemerintah Kabupaten Nganjuk dan Dinas Pariwisata Kabupaten Nganjuk guna 
meningkatkan jumlah kunjungan museum khususnya bagi para pelajar.

Selain berbagai upaya dari pihak pemerintah daerah, kesadaran masyarakat juga sangat penting untuk menjadikan prasasti Anjuk Ladang ini sebagai sumber pembelajaran sejarah. Hal itu dapat diketahui dari sikap masyarakat terhadap keberadaan prasasti Anjuk Ladang itu sendiri. Peran pemerintah Kabupaten Nganjuk serta masyarakat sangat dibutuhkan dalam upaya melestarikan prasasti Anjuk Ladang sebagai warisan sejarah bangsa. Untuk itu perlu adanya program-program dari pemerintah untuk lebih meningkatkan kesadaran masyarakat akan pentingnya sejarah Nasional.

Prasasti Anjuk Ladang selain merupakan salah satu benda cagar budaya peninggalan juga berpotensi untuk dijadikan sebagai sumber pembelajaran sejarah bagi para pelajar. Hal itu sekaligus dapat meningkatkan kecintaan para pelajar terhadap sejarah bangsanya sendiri. Jika dilihat dari sejarahnya prasasti Anjuk Ladang ditemukan di dekat sebuah candi yang bernama Candi Lor. Candi Lor adalah salah satu peninggalan $\mathrm{Mpu}$ Sindok dan merupakan bangunan suci agama Hindu. Maka jika prasasti Anjuk Ladang dan Candi Lor dikaitkan dengan sumber pembelajaran sejarah termasuk benda-benda peninggalan masa Hindu.

Berdasarkan Kurikulum Satuan Tingkat Pendidikan, peninggalan- peninggalan Hindu merupakan materi pembelajaran IPS kelas VII semester 2, yaitu terdapat dalam standar kompetensi 5 Memahami perkembangan masyarakat sejak masa Hindu-Budha sampai sekarang. Tepatnya Kompetensi dasar 5.1 Mendeskripsikan perkembangan masyarakat, kebudayaan dan pemerintahan pada masa Hindu-Budha, serta peninggalanpeninggalannya. Oleh karena itu prasasti Anjuk Ladang sangat berpotensi sebagai sumber pembelajaran IPS terutama bagi satuan pendidikan SMP kelas VII.

Sudah menjadi tugas bagi tenaga pendidik untuk menemukan benda-benda sekitar yang berpotensi untuk dijadikan sebagai sumber pembelajaran. Dan tugas bagi pemerintah untuk membuat kebijakan mengenai pelestarian benda-benda peninggalan sejarah tersebut agar dapat terus dijadikan sebagai sumber pembelajaran sejarah di masa mendatang.

\section{Penutup}

Prasati ini awalnya ditemukan di dekat sebuah candi yang bernama Candi Lor. Candi Lor terdapat di desa Candirejo Kecamatan Loceret Kabupaten Nganjuk, atau kurang lebih empat kilometer sebelah selatan dari pusat pemerintahan Kabupaten Nganjuk. Menurut sejarah prasasti ini dibuat atas perintah Mpu Sindok pada tahun 859 saka atau 937 masehi. Pasasti ini dibuat sebagai tetenger adanya tugu kemenangan atau Jayastamba yang berupa bangunan suci Candi Lor, sebagai ungkapan rasa terima 
kasih Mpu Sindok kepada masyarakat Anjuk Ladang yang telah membantu dalam peperangan melawan pasukan melayu dari kerajaan Sriwijaya.

Isi dari prasasti tersebut adalah penetapan wilayah Anjuk Ladang sebagai daerah perdikan sima swatantra. Artinya wilayah Anjuk Ladang dibebaskan dari tanggung jawab membayar pajak. Hasil bumi yang dulu digunakan untuk membayar pajak dapat digunakan untuk merawat bangunan suci Candi Lor tersebut.

Mengingat sejarahnya yang penting bagi bangsa Indonesia, serta berdasarkan Kurikulum Satuan Tingkat Pendidikan SMP kelas VII semester 2 yaitu standar kompetensi 5 Memahami perkembangan masyarakat sejak masa Hindu-Budha sampai sekarang, tepatnya Kompetensi dasar 5.1 Mendeskripsikan perkembangan masyarakat, kebudayaan dan pemerintahan pada masa Hindu-Budha, serta peninggalanpeninggalannya. Maka prasasti ini sangat sesuai dan berpotensi sebagai sumber pembelajaran sejarah.

\section{Daftar Pustaka}

Adji, K.B. 2012. Buku Pintar Raja-Raja Jawa Dari Kalingga Hingga Kesultanan Yogyakarta mengungkap Sejarah dan Biografi Para Raja Berdasar Fakta Terbaru. Yogyakarta: Araska.

Darini, R. 2013. Sejarah Kebudayaan Indonesia Masa Hindu-Budha. Yogyakarta: Ombak.

Dinas Pariwisata Dan Kebudayaan Kabupaten Nganjuk. 2007. Katalog
Koleksi Arkeologis Museum Anjuk Ladang Kabupaten Nganjuk.

2008. Katalog Koleksi Arkeologis 2 Museum Anjuk Ladang Kabupaten Nganjuk.

Harimintadji, dkk. 2003. Nganjuk dan Sejarahnya. Nganjuk: Yayasan Salepuk.

Kochhar, S.K. 2008. Teaching Of History. Jakarta: Grasindo.

Lombart, D. 2005. Nusa Jawa: Silang Budaya Warisan Kerajaan-Kerajaan Konsentris. Jakarta: Gramedia Pustaka Utama.

Miles, M.B dan Huberman, M. 1992. Analisis Data Kualitatif. Jakarta: Universitas Indonesia Press.

Moloeng. L. J. 2012. Metode Penelitian Kualitatif. Bandung: PT. Remaja

Rosdakarya.

Nazir, M. 2009. Metode Penelitian. Bogor: Ghalia Indonesia.

Pemerintah Kabupaten Daerah Tingkat II Madiun. 1980. Sejarah Kabupaten Madiun. Madiun.

Poesponegoro, M.D. 2008. Sejarah Nasional Indonesia II Zaman Kuno. Jakarta: Balai Pustaka.

Pusat Pembinaan dan Pengembangan Bahasa. 1999. Kamus Besar Bahasa Indonesia Edisi II. Jakarta: Balai Pustaka.

Sanjaya, W. 2009. Perencanaan dan Desain Sistem Pembelajaran. Jakarta: Kencana Prenada Media Group.

2009. Strategi Pembelajaran Berorientasi Standar Proses Pendidikan. Jakarta: Kencana Prenada Media Group. 
Slameto. 1991. Proses Belajar Mengajar Dalam Sistem Kredit Semester (SKS). Jakarta: Bumi Aksara.

Silalahi, A. G. 2003. Metodologi Penelitian Dan Studi Kasus. Sidoarjo: Mitra Media.

Sugiyono. 2008. Metode Penelitian Kuantitatif Kualitatif Dan R\&D. Bandung: Alfabeta.

Sukmadinata, S. 2007. Metode Penelitian Pendidikan. Bandung: PT. Remaja Rosdakarya.

Sutopo, H.B. 2002. Metodologi Penelitian Kualitatif. Surakarta: Sebelas Maret University Press.

Umar, H. 2011. Metode Penelitian Untuk Skripsi Dan Tesis Bisnis. Jakarta: Rajagrafindo Persada.

Usman, H dan Akbar, P.S. 2003. Metodologi Penelitian Sosial. Jakarta: Bumi Aksara.

Pramitahilala.blogspot.co.id/2012/03/fungs i-prasasti.html (Diakses 09-01-2016 17.30 WIB).

http://riviera17.blogspot.co.id/2012/09/at radisi-sejarah-di-berbagai-daerahdi.html (Diakses 7-03-2016 11:11) 